\title{
Is there a Mendelian transmission ratio distortion of the c.429_452dup(24bp) polyalanine tract ARX mutation?
}

\author{
Cheryl Shoubridge ${ }^{\star, 1,2}$, Alison Gardner ${ }^{1}$, Charles E Schwartz ${ }^{3}$, Anna Hackett ${ }^{4}$, Michael Field ${ }^{4}$ and \\ Jozef Gecz ${ }^{\star, 1,2}$
}

Intellectual disability is common. Aristaless-related homeobox $(A R X)$ gene is one of the most frequently mutated and pleiotropic genes, implicated in 10 different phenotypes. More than half of $\sim 100$ reported cases with $A R X$ mutations are due to a recurrent duplication of $24 \mathrm{bp}, \mathrm{c.429} 452 \mathrm{dup}$, which leads to polyalanine tract expansion. The excess of affected males among the offspring of the obligate carrier females raised the possibility of transmission ratio distortion for the c.429_452dup mutation. We found a significant deviation from the expected Mendelian 1:1 ratio of transmission in favour of the c.429_452dup $A R X$ mutation. We hypothesise that the preferential transmission of the c.429_452dup mutation may be due to asymmetry of meiosis in the oocyte. Our findings may have implications for genetic counselling of families segregating the c.429_452dup mutation and allude to putative role of $A R X$ in oocyte biology.

European Journal of Human Genetics (2012) 20, 1311-1314; doi:10.1038/ejhg.2012.61; published online 11 April 2012

Keywords: intellectual disability; polyalanine tract expansions; Mendelian transmission; $A R X$; meiotic drive

\section{INTRODUCTION}

Mutations in the Aristaless-related homeobox $(A R X)$ gene are frequent and pleiotrophic, giving rise to non-syndromic intellectual disability, infantile spasms or serious brain malformations. ${ }^{1}$ More than half of the $A R X$ cases reported are due to polyalanine expansion mutations, in two different polyalanine tracts. The c.429-452dup mutation affecting the second tract is the most frequent $A R X$ mutation. Follow-up work on these c.429-452dup families revealed a greater than expected number of affected males among the offspring of the obligate carrier females.

According to the fundamental principle of Mendelian genetics, two alleles of a diploid locus have an equal probability (50:50) to be transmitted to an offspring. The deviation from this rule is known as transmission ratio distortion (TRD). ${ }^{2}$ There are several examples of TRD suggested in human genetics, however this phenomenon remains inconclusive in man, highlighting the importance of determining this phenomenon robustly. In the case of autosomal dominant myotonic dystrophy, TRD has been reported in live-born offspring from affected female parents but not affected male parents. ${ }^{3-5}$ When looking at meioses from unaffected parents heterozygote for different repeat lengths (non-disease causing) at the DM locus, there was a significant distortion in favour of transmission of the larger allele in males. ${ }^{6}$ In contrast, no TRD was determined for any allele length when sperm from heterozygous unaffected donors were analysed ${ }^{7}$ or when pre-natal diagnoses were analysed from either affected mothers or fathers. ${ }^{8}$
Other autosomal dominant diseases also have mixed reports of TRD. With respect to Long QT syndrome, a large study investigating over 750 nuclear families, a higher than expected transmission of the mutant allele from female carriers of type I disease and from either male or female carriers with type II disease was reported..$^{9}$ Moreover, this study indicated there was an increased transmission to female offspring. A later study of 182 families from two particular Long QT syndromes did not find the same distortion to the expected 50:50 Mendelian transmission. ${ }^{10}$ Diseases caused by expansion of CAG repeats, such as Machado-Joseph disease ${ }^{11,12}$ and spinocerebellar ataxia $7^{13}$ are suggested to show a prevalence of transmission of the mutant allele, but again have conflicting reports. Investigating transmission at two CAG disease repeat loci, TRD was noted in male meioses in live-born offspring ${ }^{11}$ and in sperm typing from MJD patients $^{14}$ and preferentially transmitted to live-born offspring by female carriers. ${ }^{12}$ A study of heterozygotes of non-disease CAG repeats in unaffected families ${ }^{15}$ and unaffected twins and parent groups ${ }^{16}$ did not find TRD in male meioses. This may be, in part, due to the difficulties in comparing the findings from normal alleles with alleles in the disease range. Interestingly, the study of Rubinsztein et al $^{15}$ found in $57 \%$ of female meiosis smaller non-disease causing $\mathrm{CAG}$ repeats, suggesting meiotic drive may occur among some nondisease causing CAG repeats sizes.

Among recessive disorders, TRD has been reported in the congenital disorder of glycosylation type Ia (CGD-Ia). ${ }^{17}$ With respect to tri-nucleotide repeats in $\mathrm{X}$-chromosome genes, a TRD in

\footnotetext{
${ }^{1}$ Department of Genetics and Molecular Pathology, SA Pathology at the Women's and Children's Hospital, North Adelaide, South Australia, Australia; 2 Department of Paediatrics, University of Adelaide, Adelaide, South Australia, Australia; ${ }^{3}$ J.C. Self Research Institute, Greenwood Genetic Center, Greenwood, SC, USA; ${ }^{4}$ Genetics of Learning Disability Service of New South Wales, Hunter Genetics, Newcastle, New South Wales, Australia

*Correspondence: Dr C Shoubridge or Professor J Gecz, Neurogenetics Laboratory, Genetics and Molecular Pathology, SA Pathology at the Women's and Children's Hospital, 72 King William Road, North Adelaide 5006, South Australia, Australia. Tel: +61 881618105 ; Fax: +61 881617342 ; E-mail: cheryl.shoubridge@adelaide.edu.au (Dr C Shoubridge) or Tel: +61 88161 6339; Fax: +61 88161 6342; E-mail: jozef.gecz@adelaide.edu.au (Professor J Gecz).
}

Received 29 August 2011; revised 7 March 2012; accepted 8 March 2012; published online 11 April 2012 
favour of the mutant alleles of intermediate length of FMR1 has been shown in the X-linked Fragile $\mathrm{X}$ syndrome, ${ }^{18}$ but for neither the FRAXA nor the FRAXE loci when common, intermediate pre- and full-mutation alleles were analysed separately. ${ }^{19}$

Similar to FMR1, ARX is located on the $\mathrm{X}$ chromosome and as such, heterozygote carrier females can transmit either the normal or mutant allele to their daughters and sons. If a daughter inherits the mutant allele from the carrier mother and a normal allele from her unaffected father, she too will be a heterozygote carrier. ${ }^{1}$ As the $A R X$ gene is randomly $\mathrm{X}$-inactivated, these women will have half of the $A R X$-expressing cells with normal $A R X$ and half with the mutant $A R X$. However, if a son inherits the mutant allele he will be affected as there is no ARX paralog on the $\mathrm{Y}$ chromosome and all $A R X$-expressing cells will produce the mutant version.

In this study, we have investigated the transmission ratio of the c.429-452dup mutation in a large cohort of published and unpublished $A R X$ families. We have found that contrary to the expectation of Mendelian genetics, carrier females preferentially transmit the c.429-452dup mutation to the next generation as judged by significantly skewed numbers of affected males versus normal males.

\section{MATERIALS AND METHODS}

For the purpose of assessing the transmission ratio of the c.429-452dup mutation, we collected and assessed all published families $(n=33)$ as well as some unpublished pedigrees $(n=6)$ segregating the c.429-452dup mutation (see Table 1 and references therein). We counted the number of obligate carrier females and the number of normal and affected males they had. All families analysed had at least two affected males to correct for the ascertainment bias (see below). We did not score any clinically affected females, albeit rare, as the contribution of the c.429-452dup mutation to their phenotype has not yet been established.

\section{Statistical analaysis}

The null hypothesis we tested was the Mendelian X-chromosome allele segregation ratio of 50:50. To prevent ascertainment bias, we excluded all probands from our transmission ratio analysis, automatically removing any families with a single affected male. We used the Chi-square test to establish the significance of our findings. A Chi-square table with one degree of freedom assesses the number of possible outcomes minus one (either affected or unaffected). A $P$-value of less than 0.05 was used to indicate statistical significance.

\section{RESULTS}

A total of 39 families segregating the ARX c.429-452dup mutation were analysed (Table 1). All together, we counted 281 females, of which 137 were presumed non-carriers or not tested and 144 were carriers (Table 1). The 144 carrier females had 301 sons with 188 affected males (both alive and deceased) and 98 unaffected males $\left(\chi^{2}=28.32 ; P<0.0001\right.$; Table 2$)$. Removal of the 39 probands from the analysis to correct for the ascertainment left 149 affected males and 98 normal males, a total of 247 male offspring. The expected Mendelian segregation ratio from this cohort would be 123.5 males in each clinical category. The distortion of the transmission ratio to 149:98 was $60 \%$ in favour of the males with the c.429-452dup mutation. When tested using Chi-square $\left(\chi^{2}=10.53\right)$ it was significant at $P<0.002$ (Table 2). To address a possible ascertainment bias, we also used a more stringent approach by removing two probands from the nine MRX families and one proband from all other families, with a remaining total of 140 affected males and 98 normal males. This conservative test still gave significant results $\left(\chi^{2}=7.412\right.$; $P<0.0065)$.
Table 1 Numbers of carrier females and offspring with the c.429-452dup mutation in $A R X$

\begin{tabular}{|c|c|c|c|c|c|c|}
\hline Family & $\begin{array}{l}\text { Female } \\
\text { carriers }\end{array}$ & $\begin{array}{c}\text { Affected } \\
\text { male }\end{array}$ & $\begin{array}{c}\text { Unaffected } \\
\text { male } \\
\text { alive }+ \text { dec }\end{array}$ & $\begin{array}{c}\text { Unaffected } \\
\text { female }\end{array}$ & $\begin{array}{l}\text { Total no. } \\
\text { of } \\
\text { offspring }\end{array}$ & Reference \\
\hline MRX43 & 3 & 4 & 3 & 1 & 11 & 36 \\
\hline P73-MRX & 4 & 5 & 2 & 2 & 13 & 37 \\
\hline MRX76 & 2 & 7 & 3 & 3 & 15 & 38 \\
\hline PRTS & 1 & 2 & 1 & 0 & 4 & 39 \\
\hline MRX36 & 3 & 4 & 3 & 1 & 11 & 39 \\
\hline Fam 1 & 3 & 4 & 1 & 2 & 10 & 32 \\
\hline Fam 2 & 2 & 2 & 1 & 3 & 8 & 32 \\
\hline Fam 3 & 1 & 2 & 1 & 3 & 7 & 32 \\
\hline Fam A & 2 & 4 & $0+2 \mathrm{dec}$ & 5 & 13 & 40 \\
\hline Fam B & 5 & 7 & 4 & 9 & 26 & 40 \\
\hline P34 & 1 & 2 & 0 & 0 & 3 & 41 \\
\hline P104 & 2 & 5 & 5 & 2 & 14 & 41 \\
\hline P106 & 2 & 2 & 0 & 0 & 4 & 41 \\
\hline T37 & 3 & 3 & $1+1 \mathrm{dec}$ & 2 & 10 & 41 \\
\hline ISSX & 5 & 7 & 5 & 4 & 21 & 42 \\
\hline PRTS & 9 & 13 & $6+2 \mathrm{dec}$ & 14 & 44 & 20 \\
\hline MRX32 & 8 & 6 & 5 & 3 & 22 & 43 \\
\hline MRX29 & 4 & 8 & $4+4 \mathrm{dec}$ & 2 & 22 & 44 \\
\hline MRX38 & 3 & 6 & 3 & 11 & 23 & 45 \\
\hline MRX33 & 3 & 6 & 3 & 5 & 17 & 43 \\
\hline Thai & 5 & 3 & 2 & 3 & 13 & 46 \\
\hline Brazil & 3 & 4 & 3 & 1 & 11 & 47 \\
\hline MRX87 & 4 & 5 & $3+1 \mathrm{dec}$ & 4 & 17 & 48 \\
\hline Fam 1 & 4 & 4 & $0+1 \mathrm{dec}$ & 2 & 11 & 34 \\
\hline Fam 2 & 2 & 2 & 1 & 0 & 5 & 34 \\
\hline Fam3 & 5 & 4 & $1+1 \mathrm{dec}$ & 3 & 14 & 34 \\
\hline Fam 4 & 6 & 7 & $5+1 \mathrm{dec}$ & 7 & 26 & 34 \\
\hline Fam 5 & 4 & 3 & 2 & 2 & 11 & 34 \\
\hline Famila 1 & 2 & 2 & 1 & 2 & 7 & 49 \\
\hline Family A & 2 & 2 & 1 & 2 & 7 & 50 \\
\hline Family B & 2 & 4 & 2 & 1 & 9 & 50 \\
\hline Family C & 1 & 2 & 0 & 0 & 2 & 50 \\
\hline $\begin{array}{l}\text { XLMR } \\
\text { family }\end{array}$ & 5 & 5 & $2+1 \mathrm{dec}$ & 2 & 14 & 51 \\
\hline K8906 & 6 & 5 & 2 & 8 & 21 & Unpublished \\
\hline K8954 & 5 & 9 & 4 & 5 & 23 & Unpublished \\
\hline K8565 & 6 & 6 & $3+1 \mathrm{dec}$ & 3 & 19 & Unpublished \\
\hline K9037 & 3 & 6 & 3 & 5 & 17 & Unpublished \\
\hline 8450 & 8 & 10 & 9 & 12 & 39 & Unpublished \\
\hline Fx391 & 5 & 6 & 3 & 3 & 17 & Unpublished \\
\hline TOTAL & 144 & 188 & $98+15$ & 137 & 581 & \\
\hline
\end{tabular}

Across the 39 families evaluated, there were also an additional 15 males born to carrier females that were indicated as deceased on respective pedigrees. In the majority of these cases, the genotype, cause of death and the age at which they died was not known. If we conservatively assume that these males were not affected, that is, did not carry the c.429-452dup mutation and include in the analysis, the expected transmission of the mutant allele was still distorted $\left(\chi^{2}=4.95 ; P<0.05\right)$.

\section{DISCUSSION}

Our data suggest that there is a distortion of the expected Mendelian transmission ratio of the $A R X$ alleles in favour of the deleterious c.429-452dup mutation. This finding may have implications for genetic counselling of families segregating this particular mutation. 
Table 2 Chi-square goodness of fit analysis of transmission of the mutant c.429-452dup ARX mutant allele to male offspring

\begin{tabular}{lcrr}
\hline & Affected males & Unaffected males & $\chi^{2}$ analysis \\
\hline Total male offspring from 144 carrier females & $188(66 \%)$ & $98(34 \%)$ & $28.32, P<0.0001$ \\
Male offspring proband excluded & $149(60 \%)$ & $98(40 \%)$ & $10.53, P=0.0012$ \\
& & $113(43 \%)$ & $(P<0.002)$ \\
Male offspring (alive and deceased $\left.{ }^{\mathrm{a}}\right)$ & $149(57 \%)$ & $4.95, P=0.026$ \\
& & $(P<0.05)$ \\
\hline
\end{tabular}

alf genotype unknown at time of death, individual is assumed unaffected

To assess whether the TRD is seen also for other ARX mutations, we attempted to extend our analysis to families with the c.304ins(GCG) ${ }_{7}$ mutation. This particular mutation leads to expansion of the first polyalanine tract and is associated with more severe clinical outcomes of X-linked infantile spasms, ${ }^{20-24}$ infantile epileptic-dyskinetic encephalopathy $^{22}$ or Ohtahara syndrome. ${ }^{25}$ However, of the 11 published families with this mutation, many include only a single affected individual, thereby excluding them from this type of analysis. Mouse models of both of these mutations have recently been generated. ${ }^{26,27}$ However, there is no data as yet available regarding the transmission of the mutant alleles. Provided the TRD holds true in these knock-in mice, it will provide an opportunity to investigate the molecular mechanisms of this phenomenon in greater detail.

The causes underlying TRD include segregation distortion, which might be due to selection, and meiotic drive. Segregation distortion typically occurs after meiosis, but prior to fertilisation. We cannot formally rule out that a specific cis-allele at another locus, in a close proximity to the $A R X$ gene, is responsible for this transmission distortion rather than the $A R X$ mutation itself. However, this is unlikely given the recurrent (in contrary to the identity by descent) origin of the c.429-452dup mutations. ${ }^{20}$ The deviation from the Mendelian inheritance may occur as a result of post-fertilisation lethality of embryos or neonates of a particular genotype. TRD was reported for myotonic dystrophy, an autosomal dominant disorder with anticipation, where preferential transmission of the longer alleles (from heterozygous carrier females) had been observed. ${ }^{4}$ Although subsequent studies have narrowed down the window of TRD to the time prior to pre-implantation, the mechanism still remains elusive. ${ }^{28}$ In the case of the c.429-452dup mutation in $A R X$, we would not expect an increase in lethality of the embryo carrying normal, maternally derived $A R X$ alleles, effectively ruling out this type of deviation from Mendelian inheritance as an explanation.

Meiotic drive, on the other hand, requires TRD to occur during female meiosis. This means that the resulting gametes are not preferentially lost nor is fertility itself affected, only the inheritance of the neutral polymorphism is reduced. ${ }^{29}$ This appears to fit with the preferential inheritance of the c.429-452dup mutation. The mechanism driving the TRD remains unknown. An elegant study directly testing meiotic drive, in particular during the second meiosis, was reported for TRD of the DDK allele at the mouse Om locus. ${ }^{30}$ Originally, the embryo lethality of DDK female cross with a male from any other inbred mouse strain was attributed to single-locus lethality model. ${ }^{31}$ However, in the study by $\mathrm{Wu}$ et $a l,{ }^{30}$ the male pronuclei, female pronuclei and second polar bodies were recovered from single cell embryos, and the genotypes of single chromatids at the $\mathrm{Om}$ locus and the associated centromeres were established. This study demonstrated preferential segregation of chromatids carrying the DDK allele at the $\mathrm{Om}$ locus to the maternal pronucleus and the reciprocal preferential segregation of chromatid carrying the wild-type allele to second polar body. This only occurred when the dyad obtained from the first meiosis was heteromorphic, that is, recombined between the centromere and the Om locus. Essentially, this means that TRD only occurs when it is possible for the ova to make a segregational choice between the DDK and Wt alleles during meiosis MII. This is consistent with non-random segregation. Of interest, the authors note that the levels of distortion to transmission of the DDK allele show striking uniformity with TRD in univalent $\mathrm{X}$ chromosomes in $\mathrm{MI}$, in mouse and human Robertsonian translocations. ${ }^{30}$ Similar to these observations, we identified comparable levels of distortion of the transmission of the c.429-452dup mutation in ARX to male offspring in our study. This similarity may indicate the asymmetry of the oocyte meiotic spindle, occurring at either MI or MII, as the common underlying mechanism of TRD. The mechanism of asymmetry of meiosis in the oocyte having an important role in TRD is further supported by cases of de novo mutation of the c.429-452dup ${ }^{32-34}$ and also c.430-456dup, ${ }^{35}$ both identified through maternal gonadal mosaicism. There are no reports to date of gonadal mosaicism in the (grand)father for any expanded polyalanine tracts in ARX. Taken together, a better understanding of the role of $A R X$ in oocyte maturation may shed light on the forces underlying the phenomenon of TRD.

\section{CONFLICT OF INTEREST}

The authors declare no conflict of interest.

\section{ACKNOWLEDGEMENTS}

We thank the families for their participation in the project. We also thank the many clinical geneticists and genetic counsellors at the GOLD NSW service and Greenwood Genetic Center for evaluating many of the families. This work has been supported in part by NHMRC grants 400121 and 508043 to JG, and 408402 and 1002732 to CS and from NICHD USA (HD26202) to CES and a grant from the South Carolina Department of Disabilities and Special Needs (SCDDSN). In memory of Ethan Francis Schwartz, 1996-1998.

1 Shoubridge C, Fullston T, Gecz J: ARX spectrum disorders: making inroads into the molecular pathology. Hum Mutat 2010; 31: 889-900.

2 Lyttle TW: Cheaters sometimes prosper: distortion of mendelian segregation by meiotic drive. Trends Genet 1993; 9: 205-210.

3 Chakraborty R, Stivers DN, Deka R, Yu LM, Shriver MD, Ferrell RE: Segregation distortion of the CTG repeats at the myotonic dystrophy locus. Am J Hum Genet 1996; 59: 109-118.

4 Magee AC, Hughes AE: Segregation distortion in myotonic dystrophy. J Med Genet 1998; 35: 1045-1046.

5 Martorell L, Cobo AM, Baiget M, Naudo M, Poza JJ, Parra J: Prenatal diagnosis in myotonic dystrophy type 1 . Thirteen years of experience: implications for reproductive counselling in DM1 families. Prenat Diagn 2007; 27: 68-72.

6 Carey N, Johnson K, Nokelainen P et al: Meiotic drive at the myotonic dystrophy locus? Nat Genet 1994; 6: 117-118.

7 Leeflang EP, McPeek MS, Arnheim N: Analysis of meiotic segregation, using singlesperm typing: meiotic drive at the myotonic dystrophy locus. Am J Hum Genet 1996; 59: 896-904. 
8 Zunz E, Abeliovich D, Halpern GJ, Magal N, Shohat M: Myotonic dystrophy-no evidence for preferential transmission of the mutated allele: a prenatal analysis Am J Med Gene A 2004; 127A: 50-53.

9 Imboden M, Swan H, Denjoy I et al: Female predominance and transmission distortion in the long-QT syndrome. N Engl J Med 2006; 355: 2744-2751.

10 Berge KE, Haugaa KH, Fruh A et al: Molecular genetic analysis of long QT syndrome in Norway indicating a high prevalence of heterozygous mutation carriers. Scand J Clin Lab Invest 2008; 68: 362-368.

11 Ikeuchi T, Igarashi S, Takiyama Y et al: Non-Mendelian transmission in dentatorubralpallidoluysian atrophy and Machado-Joseph disease: the mutant allele is preferentially transmitted in male meiosis. Am J Hum Genet 1996; 58: 730-733.

12 Riess O, Epplen JT, Amoiridis G, Przuntek H, Schols L: Transmission distortion of the mutant alleles in spinocerebellar ataxia. Hum Genet 1997; 99: 282-284.

13 Monckton DG, Cayuela ML, Gould FK, Brock GJ, Silva R, Ashizawa T: Very large $(\mathrm{CAG})(\mathrm{n}) \mathrm{DNA}$ repeat expansions in the sperm of two spinocerebellar ataxia type 7 males. Hum Mol Genet 1999; 8: 2473-2478.

14 Takiyama Y, Sakoe K, Soutome M et al: Single sperm analysis of the CAG repeats in the gene for Machado-Joseph disease (MJD1): evidence for non-Mendelian transmission of the MJD1 gene and for the effect of the intragenic CGG/GGG polymorphism on the intergenerational instability. Hum Mol Genet 1997; 6: 1063-1068.

15 Rubinsztein DC, Leggo J: Non-Mendelian transmission at the Machado-Joseph disease locus in normal females: preferential transmission of alleles with smaller CAG repeats. J Med Genet 1997; 34: 234-236.

16 MacMillan JC, Voisey J, Healey SC, Martin NG: Mendelian segregation of normal CAG trinucleotide repeat alleles at three autosomal loci. J Med Genet 1999; 36: 258-259.

17 Schollen E, Kjaergaard S, Martinsson T et al: Increased recurrence risk in congenital disorders of glycosylation type la (CDG-la) due to a transmission ratio distortion. J Med Genet 2004; 41: 877-880.

18 Drasinover V, Ehrlich S, Magal $\mathrm{N}$ et al: Increased transmission of intermediate alleles of the FMR 1 gene compared with normal alleles among female heterozygotes. Am J Med Genet 2000; 93: 155-157.

19 Teague JW, Morton NE, Dennis NR et al: FRAXA and FRAXE: evidence against segregation distortion and for an effect of intermediate alleles on learning disability. Proc Natl Acad Sci USA 1998; 95: 719-724.

20 Stromme P, Mangelsdorf ME, Shaw MA et al: Mutations in the human ortholog of Aristaless cause X-linked mental retardation and epilepsy. Nat Genet 2002; 30 441-445.

21 Wohlrab G, Uyanik G, Gross C et al: Familial West syndrome and dystonia caused by an Aristaless related homeobox gene mutation. Eur J Pediatr 2005; 164: 326-328.

22 Guerrini R, Moro F, Kato M et al: Expansion of the first PolyA tract of ARX causes infantile spasms and status dystonicus. Neurology 2007; 69: 427-433.

23 Poirier K, Eisermann M, Caubel I et al: Combination of infantile spasms, non-epileptic seizures and complex movement disorder: a new case of ARX-related epilepsy. Epilepsy Res 2008; 80: 224-228.

24 Wallerstein R, Sugalski R, Cohn L, Jawetz R, Friez M: Expansion of the ARX spectrum. Clin Neurol Neurosurg 2008; 110: 631-634.

25 Absoud M, Parr JR, Halliday D, Pretorius P, Zaiwalla Z, Jayawant S: A novel ARX phenotype: rapid neurodegeneration with Ohtahara syndrome and a dyskinetic movement disorder. Dev Med Child Neurol 2009.

26 Kitamura K, Itou Y, Yanazawa M et al: Three human ARX mutations cause the lissencephaly-like and mental retardation with epilepsy-like pleiotropic phenotypes in mice. Hum Mol Genet 2009; 18: 3708-3724.

27 Price MG, Yoo JW, Burgess DL et al: A triplet repeat expansion genetic mouse model of infantile spasms syndrome, $\operatorname{Arx}(G C G) 10+7$, with interneuronopathy, spasms in infancy, persistent seizures, and adult cognitive and behavioral impairment. $J$ Neurosci 2009; 29: 8752-8763.

28 Dean NL, Loredo-Osti JC, Fujiwara TM et al: Transmission ratio distortion in the myotonic dystrophy locus in human preimplantation embryos. Eur J Hum Genet 2006; 14: 299-306.

29 Pardo-Manuel de Villena F, Sapienza C: Nonrandom segregation during meiosis: the unfairness of females. Mamm Genome $2001 ; 12$ : 331-339.
$30 \mathrm{Wu}$ G, Hao L, Han Z et al: Maternal transmission ratio distortion at the mouse Om locus results from meiotic drive at the second meiotic division. Genetics 2005; 170 : 327-334.

31 Pardo-Manuel de Villena F, de la Casa-Esperon E, Briscoe TL, Sapienza C: A genetic test to determine the origin of maternal transmission ratio distortion. Meiotic drive at the mouse Om locus. Genetics 2000; 154: 333-342.

32 Partington MW, Turner G, Boyle J, Gecz J: Three new families with X-linked mental retardation caused by the 428-451dup(24bp) mutation in ARX. Clin Genet 2004; 66: 39-45.

33 Poirier K, Abriol J, Souville I et al: Maternal mosaicism for mutations in the ARX gene in a family with X linked mental retardation. Hum Genet 2005; 118: 45-48.

34 Nawara M, Szczaluba K, Poirier K et al: The ARX mutations: a frequent cause of X-linked mental retardation. Am J Med Genet A 2006; 140: 727-732.

35 Reish O, Fullston T, Regev M, Heyman E, Gecz J: A novel de novo 27 bp duplication of the ARX gene, resulting from postzygotic mosaicism and leading to three severely affected males in two generations. Am J Med Genet A 2009; 149A: 1655-1660.

36 Hamel BC, Smits AP, van den Helm B et al: Four families (MRX43, MRX44, MRX45, MRX52) with nonspecific X-linked mental retardation: clinical and psychometric data and results of linkage analysis. Am J Med Genet 1999; 85: 290-304.

37 Bienvenu T, Poirier K, Friocourt G et al: ARX, a novel Prd-class-homeobox gene highly expressed in the telencephalon, is mutated in X-linked mental retardation. Hum Mol Genet 2002; 11: 981-991.

38 Kleefstra T, Yntema HG, Oudakker AR et al: Localization of a gene for nonspecific X-linked mental retardation (MRX 76) to Xp22.3-Xp21.3. Am J Med Genet 2002; 110: 410-411.

39 Frints SG, Froyen G, Marynen P, Fryns JP: X-linked mental retardation: vanishing boundaries between non-specific (MRX) and syndromic (MRXS) forms. Clin Genet 2002; 62: 423-432.

40 Turner G, Partington M, Kerr B, Mangelsdorf M, Gecz J: Variable expression of mental retardation, autism, seizures, and dystonic hand movements in two families with an identical ARX gene mutation. Am J Med Genet 2002; 112: 405-411.

41 Poirier K, Lacombe D, Gilbert-Dussardier B et al: Screening of ARX in mental retardation families: consequences for the strategy of molecular diagnosis. Neurogenetics 2006; 7: 39-46.

42 Stromme P, Sundet K, Mork C, Cassiman JJ, Fryns JP, Claes S: X linked mental retardation and infantile spasms in a family: new clinical data and linkage to Xp11.4-Xp22.11. J Med Genet 1999; 36: 374-378.

43 Stepp ML, Cason AL, Finnis M et al: XLMR in MRX families 29, 32, 33 and 38 results from the dup24 mutation in the ARX (Aristaless related homeobox) gene. BMC Med Genet 2005; 6: 16

44 Hane B, Schroer RJ, Arena JF, Lubs HA, Schwartz CE, Stevenson RE: Nonsyndromic X-linked mental retardation: review and mapping of MRX29 to Xp21. Clin Genet 1996; 50: $176-183$.

45 Schutz CK, Ives EJ, Chalifoux $M$ et al: Regional localization of an X-linked mental retardation gene to Xp21.1-Xp22.13 (MRX38). Am J Med Genet 1996; 64: 89-96.

46 Rujirabanjerd S, Tongsippunyoo K, Sripo T, Limprasert P: Mutation screening of the Aristaless-related homeobox (ARX) gene in Thai pediatric patients with delayed development: first report from Thailand. Eur J Med Genet 2007; 50: 346-354.

47 Gestinari-Duarte Rde S, Santos-Reboucas CB, Boy RT, Pimentel MM: ARX mutation c.428-451dup (24bp) in a Brazilian family with X-linked mental retardation Eur J Med Genet 2006; 49: 269-275.

48 Laperuta C, Spizzichino L, D'Adamo P et al: MRX87 family with Aristaless X dup24bp mutation and implication for polyAlanine expansions. BMC Med Genet 2007; 8: 25.

49 Romero-Rubio MT, Andres-Celma M, Castello-Pomares ML, Rosello M, Ferrer-Bolufe I, Martinez-Castellano F: [ARX mutations and mental retardation of unknown etiology: three new cases in Spain]. Revista de neurologia 2008; 47: 634-637.

50 Fullston T, Finnis M, Hackett A et al: Screening and cell-based assessment of mutations in the Aristaless-related homeobox (ARX) gene. Clin Genet 2011; 80: 510-522.

51 Cossee M, Faivre L, Philippe $\mathrm{C}$ et al: ARX polyalanine expansions are highly implicated in familial cases of mental retardation with infantile epilepsy and/or hand dystonia. $A m$ J Med Genet A 2011; 155A: 98-105. 